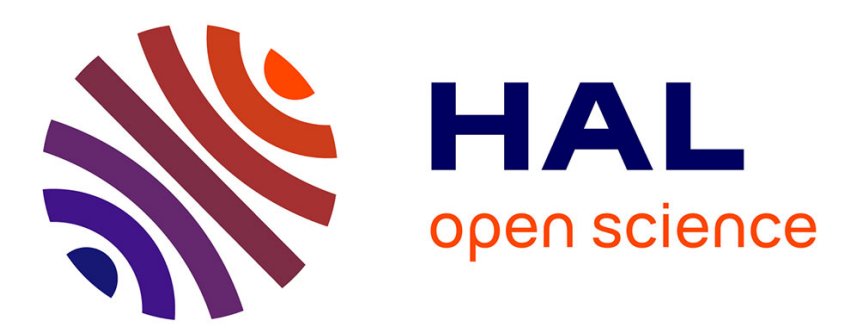

\title{
Nematic Triphenyltriazine Triesters and the Induction of the Columnar Mesophase by Fluorine Substitution
}

André A Vieira, Giliandro Farias, Wallison C J Costa, Juliana Eccher, Ivan H Bechtold, Fabien Durola, Harald Bock

\section{- To cite this version:}

André A Vieira, Giliandro Farias, Wallison C J Costa, Juliana Eccher, Ivan H Bechtold, et al.. Nematic Triphenyltriazine Triesters and the Induction of the Columnar Mesophase by Fluorine Substitution. Chemistry - A European Journal, 2021. hal-03376622

\section{HAL Id: hal-03376622 \\ https://hal.science/hal-03376622}

Submitted on 13 Oct 2021

HAL is a multi-disciplinary open access archive for the deposit and dissemination of scientific research documents, whether they are published or not. The documents may come from teaching and research institutions in France or abroad, or from public or private research centers.
L'archive ouverte pluridisciplinaire HAL, est destinée au dépôt et à la diffusion de documents scientifiques de niveau recherche, publiés ou non, émanant des établissements d'enseignement et de recherche français ou étrangers, des laboratoires publics ou privés. 
Nematic Triphenyltriazine Triesters

and the Induction of the Columnar

Mesophase by Fluorine Substitution

\author{
André A. Vieira[a], Giliandro Farias ${ }^{[b]}$, Wallison C. \\ Costa[c], Juliana Eccher[c], Ivan H. Bechtold ${ }^{[c] *}$, \\ Fabien Durola ${ }^{[d]}$, Harald Bock ${ }^{[d] *}$
}

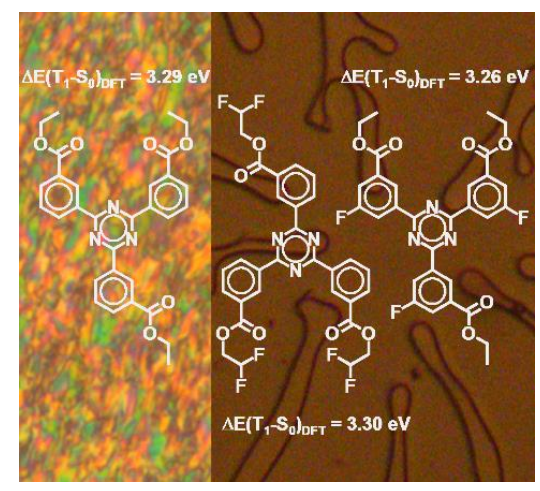

[a] Prof. A. A. Vieira, Instituto de Química, Universidade Federal da Bahia, 40170-115 Salvador, BA, Brazil

[b] G. Farias, Departamento de Química, Universidade Federal de Santa Catarina,88040-900 Florianópolis, SC, Brazil

[b] W. C. Costa, Prof. J. Eccher, Prof. I. H. Bechtold, Departamento de Física, Universidade Federal de Santa Catarina 88040-900 Florianópolis, SC, Brazil, ivan.bechtoldeufsc.br

[b] Dr. F. Durola, Dr. H. Bock, Centre de Recherche Paul Pascal, CNRS \& Université de Bordeaux, 115 av. Schweitzer, 33600 Pessac, France, harald.bockecrpp.cnrs.fr

\section{Abstract:}

Whereas their para homologs are not mesogenic, the disk-shaped triphenyltriazine meta-trialkylesters obtained via trimerization of 3-cyanobenzoic alkylester, which are configurationally more flexible, exhibit a monotropic nematic mesophase. Introduction of fluorine atoms into the alkyl chains or into the phenyl moieties leads to the appearance of an enantiotropic columnar mesophase. If fluorine is introduced both in the chains and in the phenyl moieties, only a monotropic mesophase remains. Fluorination of either the alkyl chains or the aromatic core, but not both, appears thus as a simple means of inducing or stabilizing columnar selfassembly in disk-shaped systems. As the homeotropically alignable columnar mesophase can thus be made to persist at room temperature, as energies higher than $3 \mathrm{eV}$ of the first excited triplet state are computed in agreement with the value reported for the parent arene, and as they are not fluorescent themselves, these compounds are of promise as aligning host matrices for blue-emitting TADF devices with improved light outcoupling. Dilution of a columnar with a nonmesogenic homolog induces the nematic state, indicating that the nanoscopic make-up of both mesophases is closely related.

\section{Introduction}

Alkoxycarbonyl (-COOR) substituents are very efficient in inducing columnar mesophases in polycyclic arenes. In contrast to alkoxy (-OR) and alkanoyloxy (-OCOR) substituents, where alkyl chains at least five carbon atoms long are usually necessary to make appear a mesophase in disk-shaped systems, ${ }^{[1-4]}$ already ethoxycarbonyl (-COOEt) groups, i.e. with only two alkyl carbon atoms, efficiently induce mesophases in a variety of systems.[5-7] Four such -COOR substituents are generally sufficient, whereas six alkoxy substituents are generally present in most diskshaped alkoxy-arene mesogens. [3, 4] With only three linear alkylester substituents, the formation of the columnar phase is limited to very short chains - ethyl to butyl in the case of hexaazatrinaphthylenes $1{ }^{\left[{ }^{[8]}\right.}$ solely ethyl in the

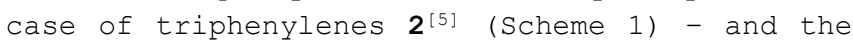
appearance of a nematic mesophase, rather rare in disk-shaped systems, is observed with moderately longer chains - with ethyl to hexyl in 1, with propyl and butyl in 2. Threefoldsymmetric systems with only three substituents are nevertheless often much easier to access synthetically.

Donor-substituted triphenyl-s-triazines such as 3 are a promising major class of thermally activated delayed fluorescence (TADF) emitters, [9-20] and parent triphenyl-s-triazine has a high triplet energy of ca. $3.05 \mathrm{eV}^{[21]}$ that allows its consideration as anisotropic host ${ }^{22-}$ 28] for blue-emitting TADF dopants whose triplet energy should be smaller than the host's to confine the excitons on the guest molecules. [29] We thus wondered whether simple triphenyltriazine triesters, accessible via trimerization of cheap methyl cyanobenzoates in triflic or chlorosulphonic acid, would exhibit columnar mesomorphism that could qualify them as large band gap anisotropic matrices for such emitters. Hexaester 4, whose cyanoisophthalate precursor is accessible from 5-aminoisophthalic acid via cumbersome Sandmeyer chemistry, [30] shows a stable columnar mesophase between 105 and $211^{\circ} \mathrm{C}$, but crystallizes upon cooling to room temperature under loss of alignment. [8] Related trithienyltriazine trialkylesters 5 show monotropic nematic mesomorphism with linear alkyl chains of at least three carbon atoms (the ethyl derivative being nonmesomorphic in contrast to 1 and 2), and also crystallize upon standing at room temperature; no columnar mesophase is observed. [31]

Two isomeric series of triphenyltriazine triesters with threefold symmetry are accessible by trimerization of methyl cyanobenzoates: para isomers 6 and meta isomers 7. The $n$-alkyl series of para homologs 6 is known ${ }^{[32]}$ and electrochromism has recently been observed with the ethyl homolog, [33] but no mesogenic properties have been reported. As the report on this series from 1963 predates the discovery of liquid crystalline self-assembly by disk-shaped molecules in 1977, [2] we reinvestigated the ethyl to pentyl homologs 6 , but this only confirmed the absence of any mesophase in this series. Better plane-filling and greater conformational multiplicity in 7 compared to 6, together with the liquid-crystallinity of the thieno homologs 5, made us nevertheless confident that meta isomers 7 might display mesogenic behavior. 

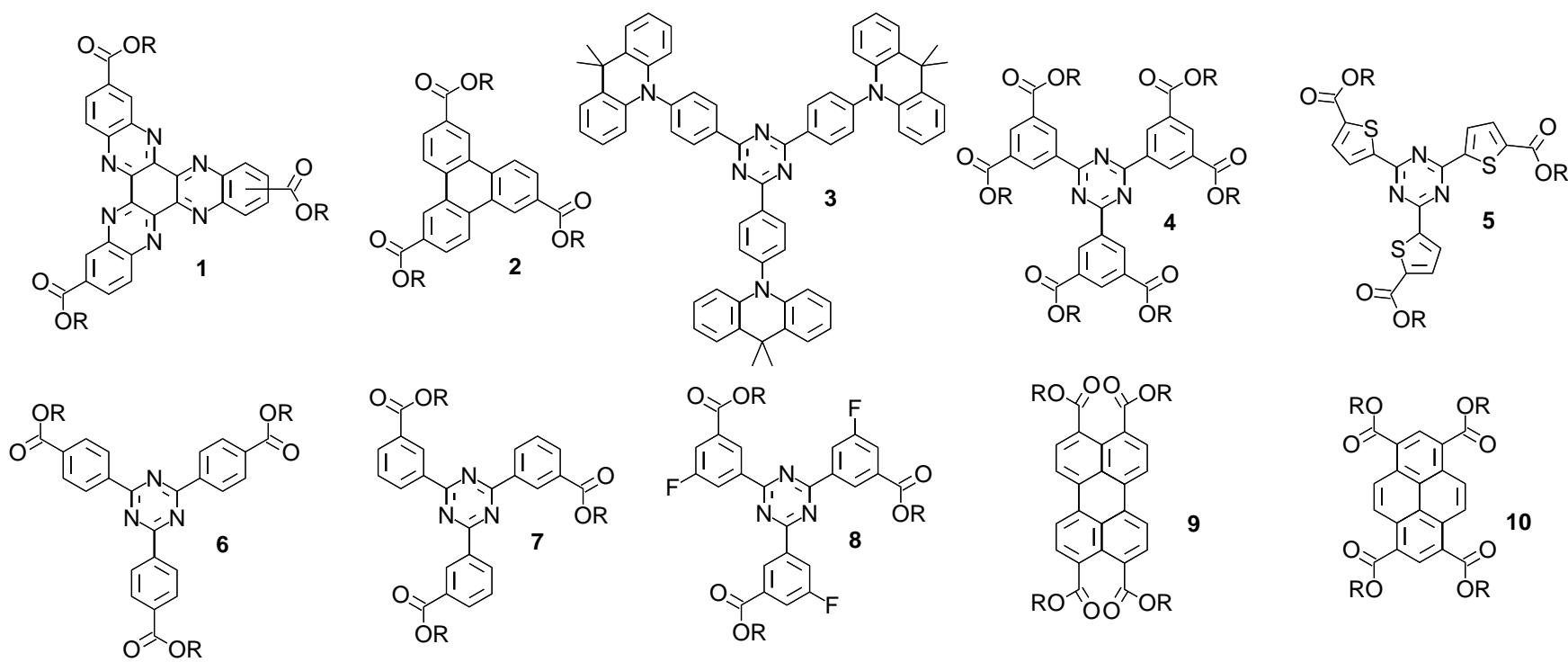

\begin{abstract}
Scheme 1. Liquid crystalline triaryltriazines 4, 5, 7 \& 8 and related systems 1, 2, 3, 6, 9 \& $\mathbf{1 0}$. R = alkyl or fluoroalkyl. Compounds discussed in the text are indexed to designate $\mathrm{R}$ as follows: $\mathbf{7}_{\mathrm{Me}}$ and $\mathbf{8}_{\mathrm{Me}}: \mathrm{R}_{\mathbf{2}} \mathrm{CH}_{3} ; \mathbf{6}_{\mathbf{E t}}, \mathbf{7}_{\mathbf{E t}}$ and $\mathbf{8}_{\mathbf{E t}}$ : $\mathrm{R}=\mathrm{CH}_{2} \mathrm{CH}_{3}$; $7_{\mathrm{Pr}}$ and $\mathbf{8}_{\mathrm{Pr}}: \mathrm{R}=\left(\mathrm{CH}_{2}\right)_{2} \mathrm{CH}_{3} ; \mathbf{7}_{\mathrm{Bu}}$ and $\mathbf{8}_{\mathrm{Bu}}: \mathrm{R}=\left(\mathrm{CH}_{2}\right)_{3} \mathrm{CH}_{3} ; \mathbf{7}_{\text {Pent }}$ and $\mathbf{8}_{\text {Pent }}: \mathrm{R}=\left(\mathrm{CH}_{2}\right)_{4} \mathrm{CH}_{3} ; \mathbf{5}_{\mathrm{Hex}}$ and $\mathbf{7}_{\mathrm{Hex}}$ : $\mathrm{R}=\left(\mathrm{CH}_{2}\right){ }_{5} \mathrm{CH}_{3} ; \mathbf{7}_{\mathrm{F} 2 \mathrm{Et}}$ and $\mathbf{8}_{\mathbf{F} 2 \mathrm{Et}}$ : $\mathrm{R}=\mathrm{CH}_{2} \mathrm{CHF}_{2} ; \mathbf{7}_{\mathrm{F} 3 \mathrm{Et}}$ and $\mathbf{8}_{\mathrm{F} 3 \mathrm{Et}}: \mathrm{R}=\mathrm{CH}_{2} \mathrm{CF}_{3} ; \mathbf{7}_{\mathrm{F} 5 \mathrm{Pr}}$ and $\mathbf{8}_{\mathrm{F} 5 \mathrm{Pr}}: \mathrm{R}=\mathrm{CH}_{2} \mathrm{CF}_{2} \mathrm{CF}_{3} ; \mathbf{7}_{\mathrm{F} 7 \mathrm{Bu}}$ and $\mathbf{8}_{\mathrm{F} 7 \mathrm{Bu}}: \mathrm{R}=\mathrm{CH}_{2}\left(\mathrm{CF}_{2}\right){ }_{2} \mathrm{CF}_{3}$
\end{abstract}

A complementary approach to induce and tune mesogenic behavior in series 6 and 7 is mixing, to favor mesophase formation over crystallization (the latter being more hindered by increase of entropy) or to allow tuning of the liquid crystalline order between columnar and nematic self-assembly. Systems with a nematic-tocolumnar phase transition would allow studies of the effect of self-assembly alone on optoelectronic properties, at same molecular makeup. Whether mixing of different homologs of 7 with different chains or mixing metasubstituted 7 with para-substituted 6 is to be privileged remained to be seen. In particular, mixing a columnar material with an electronically similar non-mesogen to reduce long-range order to obtain a nematic mesophase would be an original approach. Such an induction of a nematic phase by mixing of a non-LC into a columnar LC has previously been reported for doping of a donor-type LC with a non-mesogenic acceptor, altering significantly the electronic make-up with respect to the pure LC. [34]

\section{Results}

Whereas the thieno analogs 5 were reported to be obtained by palladium-catalyzed coupling of cyanuric acid with a tributylstannyl-substituted thiophenecarboxylic ester under microwave activation, we preferred to follow the much simpler approach to triaryltriazines by the acidcatalyzed trimerization of an appropriate benzonitrile. ${ }^{[32}$, 35] Commercial methyl 3cyanobenzoate was thus converted into the corresponding tris (methoxycarbonylphenyl)triazine $\quad \mathbf{7}_{\mathrm{Me}} \quad$ by stirring overnight in undiluted triflic acid at room temperature in $84 \%$ yield, confirming the convenience of this approach even in the presence of a methyl ester group. To obtain homologs with longer alkyl groups, three approaches were considered: a) Initial esterification of commercial 3-cyanobenzoic acid with the appropriate alkanol followed by trimerization as last step, b) direct trimerization of unprotected cyanobenzoic acid followed by final esterification, and $\mathrm{C}$ ) ester hydrolysis of $\mathbf{7}_{\mathrm{Me}}$ and subsequent re-esterification with the corresponding bromoalkane. Approach a) turned out to be inefficient because only the methyl esters trimerized efficiently, whereas longer alkyl groups led to poor trimerization yields, presumably due to better solvation in triflic acid and thus concurrent acidic hydrolysis. Approach b), in principle the most straightforward one, led to the desired triphenyltriazine triacid only in varying yields of at best $40 \%$ accompanied by considerable amounts of unidentified side products that were not trivial to separate. We thus preferred approach c), i.e. prepare the triacid by hydrolysis of the trimerized methyl ester, followed by esterification.

We synthesized the n-alkyl homologs with up to six carbons per alkyl chain. Whereas the methyl homolog $7_{\mathrm{Me}}$ is non-mesogenic, all longer alkyl derivatives ( $\left.\mathbf{7}_{\mathbf{E t}}, \quad \mathbf{7}_{\mathbf{P r}}, \mathbf{7}_{\mathbf{B u}}, \mathbf{7}_{\text {Pent }}, \mathbf{7}_{\mathbf{H e x}}\right)$ showed a monotropic nematic mesophase observable by fast cooling from temperatures above the melting point to temperatures close to room temperature (Figure 1 ). Only the propyl homolog $\mathbf{7}_{\mathbf{p r}}$ shows in addition a monotropic columnar mesophase that forms slightly above room temperature upon cooling from the nematic mesophase (Figure 2). In all cases, the mesophase is unstable at room temperature towards crystallization. Whereas the texture of the nematic phase is observed without difficulty by polarized light optical microscopy (POM) in $\mathbf{7}_{\mathbf{E t}}, \quad \mathbf{7}_{\mathbf{P r}}, \quad \mathbf{7}_{\mathrm{Bu}}$ and $\mathbf{7}_{\text {Pent }}$, trihexyl ester $\mathbf{7}_{\text {Hex }}$ crystallizes quickly, making it difficult to cool fast enough below its clearing temperature of $24.8{ }^{\circ} \mathrm{C}$ to be able to observe the appearance of the nematic texture before crystallization is complete. This contrasts with the series of trithienyltriazines 5, where the monotropic nematic mesophase of the hexyl homolog $\boldsymbol{5}_{\text {Hex }}$ was reported to show the best resilience against crystallization at room temperature. [31] 


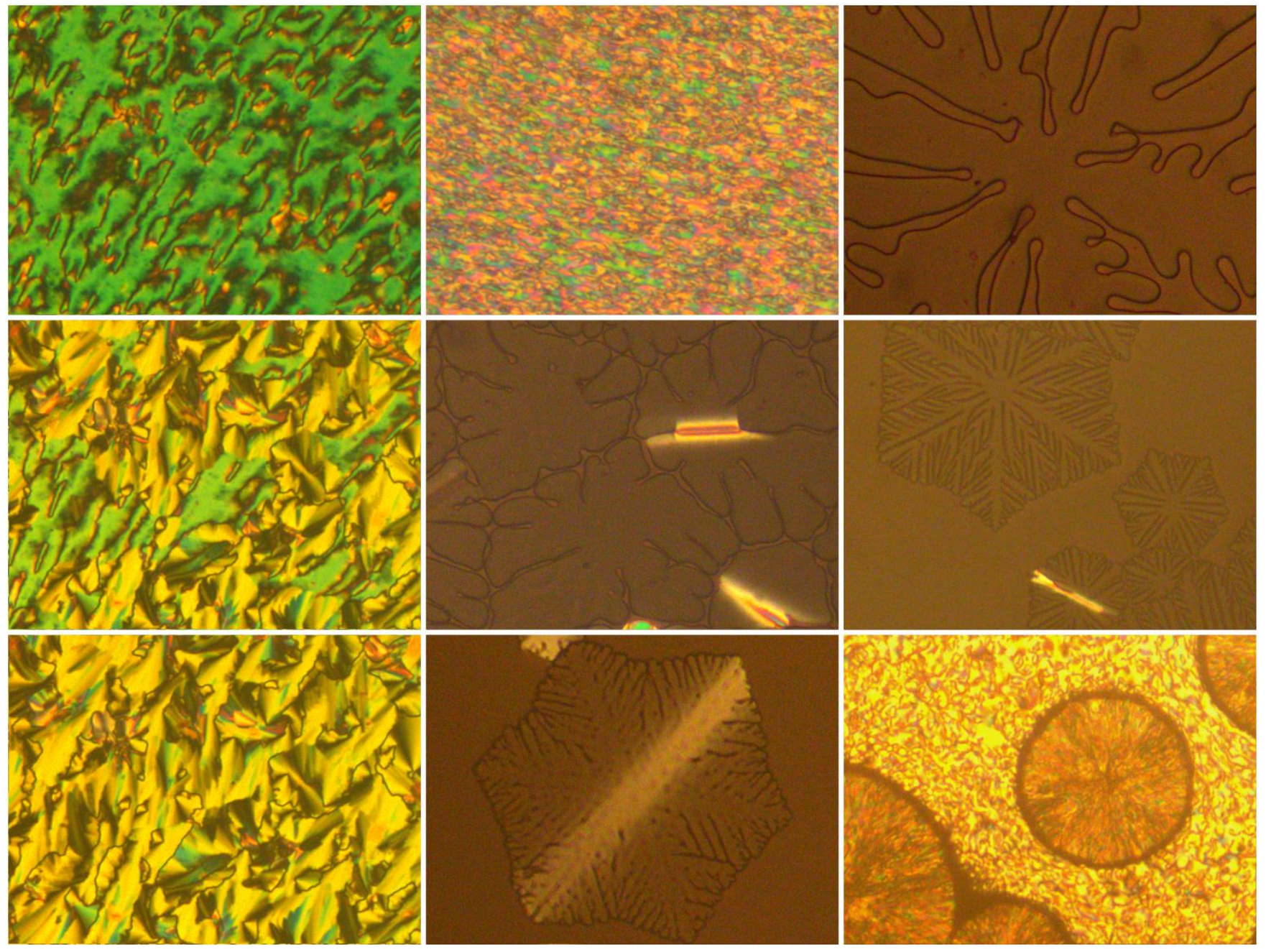

Figure 1. Textures observed between glass slides by polarized light optical microscopy with slightly uncrossed polarizers. Left column from top to bottom: $7_{\mathbf{p r}}$ on cooling in the nematic phase (greenish), during the nematic-columnar phase transition, and in the columnar phase (yellowy). Middle column: top: $\mathbf{7}_{\mathrm{Et}}$ after fast cooling to room temperature from above the melting temperature; middle and bottom: columnar phase of $\mathbf{8}_{\mathbf{m e}}$ and $\mathbf{8}_{\text {pent }}$ growing from the isotropic liquid on slow cooling. Right column: top and middle: columnar phase of $\mathbf{7}_{\mathbf{F} 2 \mathrm{Et}}$ and $\mathbf{8}_{\mathbf{F} 2 \mathrm{Et}}$ growing from the isotropic liquid on slow cooling, bottom: growth of the nematic phase of $\mathbf{8}_{\mathbf{F} 7 \mathrm{Bu}}$ (yellowy areas) from the isotropic liquid (dark border areas) in the presence of growing spherical crystalline domains.

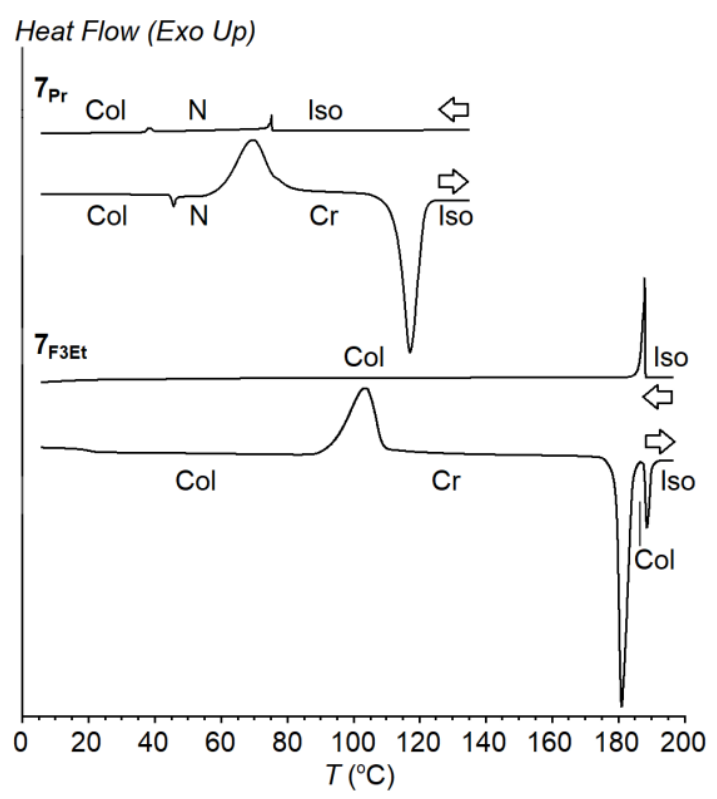

Figure 2. DSC traces, upon cooling and subsequent reheating at $10{ }^{\circ} \mathrm{C} / \mathrm{min}$, of $7_{\mathrm{Pr}}$ (monotropic nematic and columnar) and 7 F3Et (monotropic columnar), whose crystallizations are hindered on cooling and manifest themselves by exothermic peaks during reheating. $\mathrm{Cr}=$ crystalline state, Iso = isotropic liquid, $\mathrm{N}=$ nematic mesophase, $\mathrm{Col}=$ columnar mesophase.
Whereas the melting points of the homologs with even-numbered alkyl chains are higher than of those with odd-numbered chains ( $\mathbf{7}_{\mathrm{Bu}}$ and $\mathbf{7}_{\mathrm{Hex}}$ melt higher than $\mathbf{7}_{\mathbf{P r}}$ and $\mathbf{7}_{\text {pent }}$ ), the decrease of clearing temperature is almost linear with chain length from $\mathbf{7}_{\mathbf{E t}}$ to $\mathbf{7}_{\text {Hex }}$ (about $-17{ }^{\circ} \mathrm{C}$ per carbon). Aiming at increasing the viscosity of the mesophase and thus favoring a glass transition above room temperature that would stabilize the nematic state, we replaced the hydrocarbon alkyl side chains by partially fluorinated alkyl chains $-\mathrm{CH}_{2}\left(\mathrm{CF}_{2}\right)_{0-2} \mathrm{CF}_{3}$, whose increased rigidity, molecular weight and density compared to their hydrocarbon analogs would restrict the fluidity [36, 37] of the alkyl parts without hindering mesophase formation. A stabilizing effect of semi-perfluorinated side chains in disk-shaped molecules has previously been observed with hexagonal columnar triphenylene hexaethers, where both the melting and clearing points both increase upon replacement of the alkoxy chains by semiperfluorinated ones. [38, 39]

As the corresponding fluoroalkyl bromides are much more expensive than the fluoroalkanols, we used instead the triflates as esterification agents, prepared in situ from the fluoroalkanol and triflic anhydride. 
To our surprise, the obtained fluorinated homologs $7_{\text {F3Et }}, 7_{\text {F5Pr }}$ and $7_{\text {F7Bu }}$ (with $\mathrm{R}=-\mathrm{CH}_{2} \mathrm{CF}_{3}$, $\mathrm{CH}_{2} \mathrm{CF}_{2} \mathrm{CF}_{3}$ and $-\mathrm{CH}_{2} \mathrm{CF}_{2} \mathrm{CF}_{2} \mathrm{CF}_{3}$, respectively) all displayed no nematic phase, but a stable enantiotropic hexagonal columnar mesophase at elevated temperatures (see table) that directly gives way to the isotropic liquid upon heating. As the melting temperature decreases more pronouncedly than the clearing temperature upon increase of the length of the fluorinated chain, the enantiotropic mesophase range increases from $7_{\text {F3Et }}$ via $7_{\text {F5Pr }}$ to $7_{\text {F7Bu }}$ (from $8.4{ }^{\circ} \mathrm{C}$ via $20.5{ }^{\circ} \mathrm{C}$ to $22.2{ }^{\circ} \mathrm{C}$, table 1 ).

Table 1. Phase sequences of trialkoxycarbonyltriphenyltriazines $\mathbf{7}$ and $\mathbf{8}$ with transition temperatures and transition enthalpies [in brackets].

\begin{tabular}{|c|c|}
\hline Subst. & Phases with transition tempe. and enthalpies ${ }^{[a]}$ \\
\hline \multicolumn{2}{|c|}{ Non-fluorinated: } \\
\hline $7_{\text {ме }}$ & $\mathrm{Cr}-225.7^{\circ} \mathrm{C}[107.2 \mathrm{~J} / \mathrm{g}]-\mathrm{Iso}$ \\
\hline $7_{\mathrm{Et}}$ & $C r-162.3[93.4]-I s o-94.5[\mathrm{n} / \mathrm{a}][\mathrm{b}]-N$ \\
\hline $7_{\mathrm{Pr}}$ & $\mathrm{Cr}-112.2[65.1]-$ Iso $-75.3[0.9]-N-39.4[0.5]-\mathrm{Col}$ \\
\hline $7_{\mathrm{Bu}}$ & $\mathrm{Cr}-126.7[78.5]-$ Iso $-58.2[0.6]-N$ \\
\hline $7_{\text {Pent }}$ & $\mathrm{Cr}-100.7[70.4]-$ Iso $-38.4[0.4]-N$ \\
\hline $7_{\text {Hex }}$ & $C r-118.9[69.8]-$ Iso $-24.8[0.8]-N$ \\
\hline \multicolumn{2}{|c|}{ Chain-fluorinated: } \\
\hline $7_{\mathrm{F} 2 \mathrm{Et}}$ & $\mathrm{Cr}-164.4[60.5]-\mathrm{Col}-182.9[7.2]-$ Iso \\
\hline $7_{\mathrm{F} 3 \mathrm{Et}}$ & Cr $-179.2[59.9]-\operatorname{Col}-187.6[7.4]-$ Iso \\
\hline $7_{\text {F5Pr }}$ & $\operatorname{Cr}-147.2[46.8]-\operatorname{Col}-167.7[6.0]-$ Iso \\
\hline $7_{\mathrm{F} 7 \mathrm{Bu}}$ & $C r-130.9[33.2]-C o l-153.1[3.0]-$ Iso \\
\hline \multicolumn{2}{|c|}{ Core-fluorinated: } \\
\hline $8_{\text {ме }}$ & $C r-253.8[94.5]-\operatorname{Col}-262.1[13.6]-$ Iso \\
\hline $8_{\mathrm{Et}}$ & $\operatorname{Cr}-156.1[54.7]-\operatorname{Col}-253.4[13.6]-$ Iso \\
\hline $8_{\mathrm{Pr}}$ & Cr $-110.5[26.6]-$ Col $-219.6[9.9]-$ Iso \\
\hline $8_{\mathrm{Bu}}$ & $\mathrm{Cr}-110.7[55.0]-\mathrm{Col}-192.1[8.3]-$ Iso \\
\hline $8_{\text {Pent }}$ & $C r-119.7[58.1]-C o l-157.1[5.4]-$ Iso \\
\hline \multicolumn{2}{|c|}{ Core- and chain-fluorinated: } \\
\hline $8_{\mathrm{F} 2 \mathrm{Et}}$ & $\mathrm{Cr}-242.3[90.1]-$ Iso $-\sim 219[\mathrm{n} / \mathrm{a}][\mathrm{c}]-\mathrm{Col}$ \\
\hline $8_{\mathrm{F} 3 \mathrm{Et}}$ & $\mathrm{Cr}-244.9[87.6]-\mathrm{Iso}-\sim 201[\mathrm{n} / \mathrm{a}][\mathrm{c}]-\mathrm{CoI}$ \\
\hline $8_{\mathrm{F} 5 \mathrm{PF}}$ & $\mathrm{Cr}-211.3[60.5]-\mathrm{Iso}-\sim 176[\mathrm{n} / \mathrm{a}][\mathrm{c}]-\mathrm{Col}$ \\
\hline $8_{\mathrm{F} 7 \mathrm{Bu}}$ & $\mathrm{Cr}-199.2[53.7]-$ Iso $-\sim 161[\mathrm{n} / \mathrm{a}][\mathrm{c}]-N$ \\
\hline
\end{tabular}

[a] DSC onset temperatures and enthalpies at $10{ }^{\circ} \mathrm{C} / \mathrm{min}$; $\mathrm{Cr}$ = crystalline state, Iso = isotropic liquid, $\mathrm{N}=$ nematic mesophase, $\mathrm{Col}=$ hexagonal columnar mesophase; values for Cr-Iso, Cr-Col and Col-Iso transitions to enantiotropic phases on heating; values for Iso- $\mathrm{N}$ and $\mathrm{N}-\mathrm{Col}$ transitions to monotropic phases on cooling in italics. [b] The monotropic Iso-N enthalpy of $7_{\mathrm{Et}}$ could not be determined due to competing crystallization at the available DSC cooling rates. [C] The monotropic Iso-Col transitions of $\mathbf{8}_{\mathbf{F} 2 \mathbf{E t}}, \mathbf{8}_{\mathbf{F} 3 \mathbf{E}}$ and $\mathbf{8}_{\mathbf{F} 5 \mathrm{Pr}}$ and the monotropic Iso-N transition of $\mathbf{8}_{\mathbf{F} 7 \mathrm{Bu}}$ Could not be detected by DSC due to crystallization at higher temperatures, therefore for these transitions only approximate transition temperatures observed by POM on rapid cooling are given.

Amongst the perfluoroalkylmethyl and amongst the nonfluorinated varieties of $\mathbf{7}$, the trifluorethyl and ethyl derivatives $\mathbf{7}_{\mathbf{F B E t}}$ and $\mathbf{7}_{\mathbf{E t}}$ respectively show the most stable (least unstable) mesophase at room temperature, indicating that short chains are preferable for mesophase stabilization, as already observed in triphenylenes 2 . Albeit $\mathbf{7}_{\mathbf{E t}}$ has to be cooled rapidly (such as by putting a hot isotropic sample on a glass slide onto a cold metal surface) to avoid crystallization during cooling, the nematic phase held at $30^{\circ} \mathrm{C}$ does crystallize only after several days, as revealed by powder X-ray diffraction (XRD) of a quickly cooled sample (Figure 3). $7_{\text {F3Et }}$ is the only one of the three perfluoroalkylmethyl homologs that shows no crystallization peak by DSC upon cooling down from the clearing temperature to room temperature at $\quad-10{ }^{\circ} \mathrm{C} / \mathrm{min}$ (Figure 2), although, as with $\mathbf{7}_{\mathbf{E t}}$, crystallization is observed by XRD after several days.

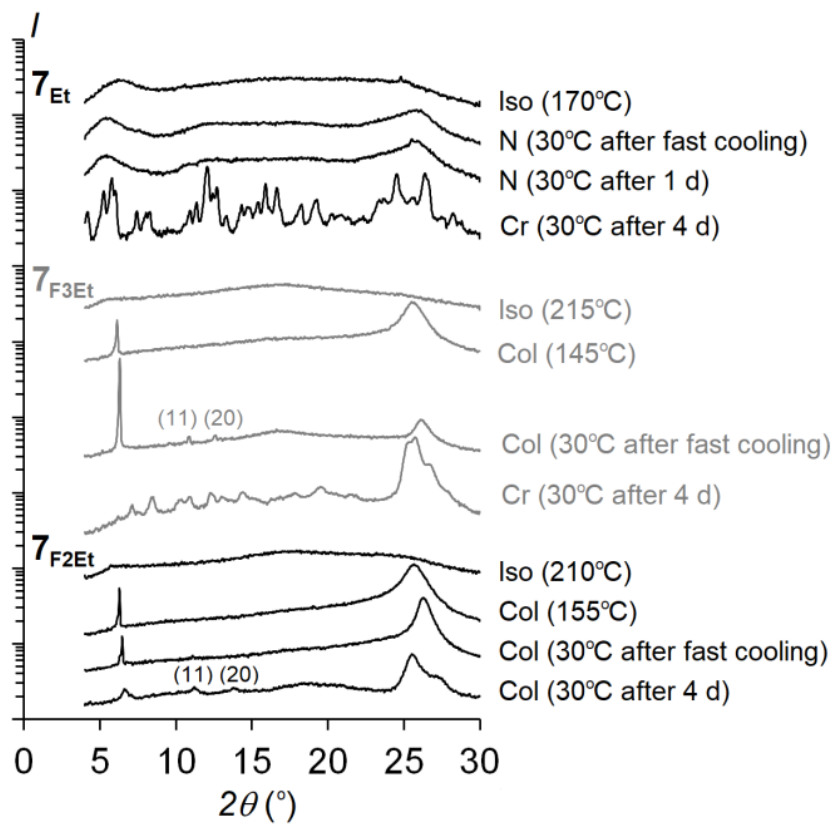

Figure 3. Powder XRD patterns of $\mathbf{7}_{\mathrm{Et}}, \mathbf{7}_{\text {F3Et }}$ and $\mathbf{7}_{\mathrm{F} 2 \mathrm{Et}}$ at different temperatures, with Miller indices of secondary peaks of the hexagonal column lattice indicated in brackets.

We wondered whether a further improvement of mesophase stability versus crystallization could be imparted by reducing the number of fluorine atoms on the ethyl moiety to reduce its symmetry and thus its tendency to crystallize, and whether this would yield columnar or nematic mesomorphism. Monofluoroethanol and its derivatives are very toxic to mammals including humans due to their ease of oxidation to monofluoroacetic acid, a potent livestock-endangering toxin of southern hemisphere plants, ${ }^{[40]}$ whereas no comparable toxicity is observed with di- and trifluoroethanol. We therefore refrained from preparing the monofluoroethyl homolog $\mathbf{7}_{\mathrm{FEt}}(\mathrm{R}=-$ $\mathrm{CH}_{2} \mathrm{CH}_{2} \mathrm{~F}$ ) and made only the difluoroethyl homolog $7_{\text {F2Et }}\left(\mathrm{R}=-\mathrm{CH}_{2} \mathrm{CHF}_{2}\right) . \mathbf{7}_{\text {F2Et }}$ exhibits a hexagonal columnar mesophase like $\mathbf{7}_{\text {F3Et }}$, but with improved enantiotropic mesophase range $\left(18.5{ }^{\circ} \mathrm{C}\right.$ vs. $8.4{ }^{\circ} \mathrm{C}$, table 1). No crystallization could be observed by XRD after 4 days at $30^{\circ} \mathrm{C}$ (Figure 3) whereas an enhancement of columnar order over that period is evident from the appearance of the initially absent (11) and (20) peaks of the hexagonal column lattice. The initial absence in the XRD of secondary lattice peaks besides the main (10) peak, also observed with $\mathbf{7}_{\mathbf{F 3 E t}}$ at elevated temperature (Figure 3), underlines the difficulty of these systems to form a column lattice of extended regularity, which is in line with the preferred formation of the rare discotic nematic mesophase in the nonfluorinated homologs.

From this tendency to form a column lattice that lacks sufficient long rang order to manifest itself by secondary lattice reflections, there is only a small step to a nematic phase made of mesoscopic rod-like columns of limited length. Both mesophases, i.e. a columnar phase lacking 
long-range lattice regularity and a nematic phase of column fragments, should exhibit only two peaks by powder XRD, one corresponding to the disk stacking distance of about $0.35 \mathrm{~nm}$, and one corresponding to the column-to-column distance of about $1.4 \mathrm{~nm}$. The difference between the two mesophases would be the shape of the latter peak: Whilst in the columnar phase, it should be rather sharp, only a diffuse broad peak can be expected in the nematic phase, as observed e.g. with $\mathbf{7}_{\mathbf{E t}}$ (Figure 3).

To see whether the fluorine-induced columnar phase of $\mathbf{7}_{\text {F2Et }}$ could be perturbed into the nematic phase by a non-mesogenic disturber of similar but not identical shape, we mixed $\mathbf{7}_{\text {F2Et }}$ with its nonfluorinated non-mesogenic para homolog $\boldsymbol{6}_{\mathbf{E t}}$. When the 1:1 mixture, prepared by solvent evaporation of a chloroform solution of the two compounds, was heated to the isotropic liquid and cooled back again, a nematic mesophase is indeed formed below $136^{\circ} \mathrm{C}$ that persists at room temperature for hours to days before crystallizing (Figure 4). Thus controlled perturbation of the columnar mesophase reduces its order to yield the nematic state, strongly supporting the assumption that the nematic state is made up of column segments as its mesoscopic constituents. [34]
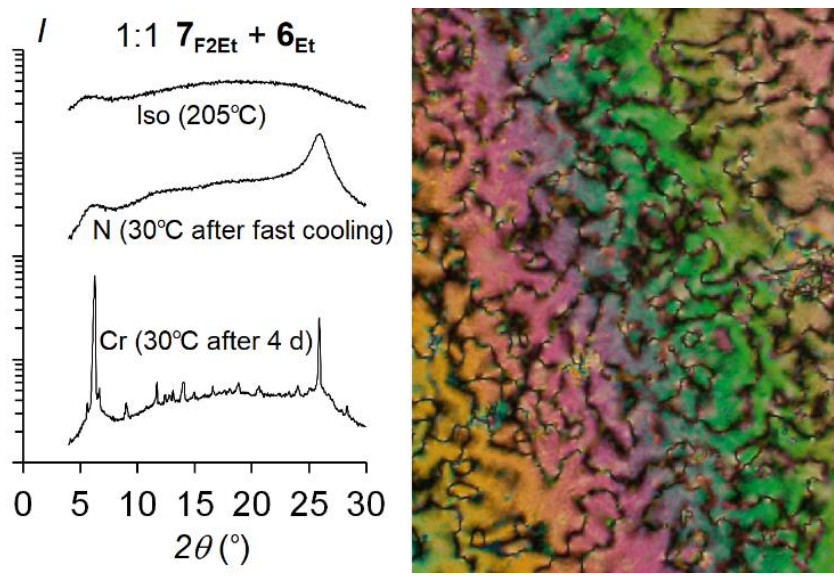

Figure 4. Left: powder XRD patterns of a 1:1 mixture of $7_{\text {F2Et }}$ and $\boldsymbol{6}_{\mathrm{Et}}$ at different temperatures; right: POM texture of the mesophase at room temperature between glass slides.

To evaluate whether a single fluorine on average per ethyl group would be sufficient to induce a columnar instead of nematic phase in $\mathbf{7}$, we also mixed $\mathbf{7}_{\mathbf{F} 2 \mathbf{E t}}$ with its non-fluorinated mesogeniC homolog $\mathbf{7}_{\mathrm{Et}}$. On cooling from the isotropic liquid, the 1:1 mixture forms a nematic phase between $128^{\circ} \mathrm{C}$ and $117{ }^{\circ} \mathrm{C}$ followed by a columnar mesophase between 117 and $38{ }^{\circ} \mathrm{C}$, whose $\mathrm{X}$-ray diffractogram shows a single intercolumn peak and a broad interdisk peak that gains in intensity and definition at lower temperatures (Figure 5). Whereas the intensification of the interdisk peak indicates an improvement of stacking regularity on lowering of temperature, the absence of higher order column lattice peaks besides the prominent main peak indicates poor long-distance periodicity of the column lattice. On cooling below $38{ }^{\circ} \mathrm{C}$, the intercolumn peak surprisingly disappears, whilst the interdisk peak remains unchanged and prominent, pointing again to the formation of a nematic phase of column fragments. POM clearly shows a nematic texture above $117{ }^{\circ} \mathrm{C}$ and a columnar texture below $117{ }^{\circ} \mathrm{C}$, but no significant texture change is apparent at $38{ }^{\circ} \mathrm{C}$. This lack of change of mesoscopic arrangement on transition from columnar to nematic below $38{ }^{\circ} \mathrm{C}$ may be due to a sufficiently high viscosity and to the absence of any newly imposed periodic order upon formation of a low-temperature nematic phase. No nematic texture could be observed, therefore it remains speculative to assume this mesophase as being reentrant nematic. ${ }^{[41]}$ As we can exclude spontaneous macroscopic alignment in the diffraction tube as a reason for the disappearance of the lattice peak, we can make the minimal statement that the long range periodicity of the higher-temperature columnar mesophase vanishes under conservation of the microscope texture, i.e. without macroscopic changes in orientation. Whilst the monotropic phase transitions at 128 and $117{ }^{\circ} \mathrm{C}$ are observed by DSC only on cooling, the phase transition at $38{ }^{\circ} \mathrm{C}$ is observed both on cooling and on subsequent reheating, as the higher viscosity at lower temperatures impedes crystallization, which occurs upon reheating with $10^{\circ} \mathrm{C} / \mathrm{min}$ only above $70{ }^{\circ} \mathrm{C}$. Even though the viscosity leads to a rugged DSC peak shape on reheating, the reoccurrence of the calorimetric transition on reheating without significant temperature hysteresis, followed by crystallization upon further heating, underlines the liquid crystalline nature of the room temperature phase. Irrespective of the nature of this room temperature mesophase, the observation of both a columnar and a nematic mesophase at higher temperatures underlines that a single fluorine atom per chain on average is sufficient to impart columnar mesomorphism in $\mathbf{7}$, but insufficient to suppress the nematic state at higher temperatures, thus allowing the observation of both phases and of the phase transition between them.
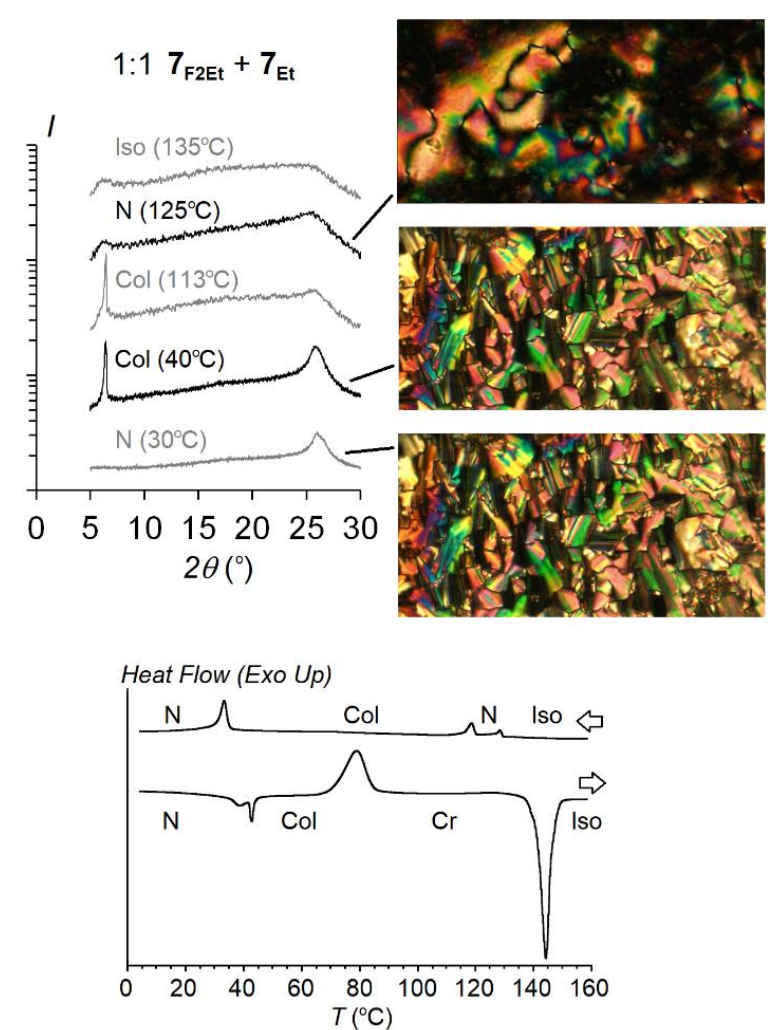

Figure 5. Top: powder XRD patterns of a $1: 1$ mixture of $7_{\text {F2Et }}$ and $7_{\mathbf{E t}}$ at different temperatures, with POM textures at $125{ }^{\circ} \mathrm{C}, 40{ }^{\circ} \mathrm{C}$ and room temperature after cooling from the isotropic state; bottom: DSC traces upon cooling and subsequent reheating at $10{ }^{\circ} \mathrm{C} / \mathrm{min}$. 
Given the systematic columnar-mesophase-inducing effect of fluorine atoms in the peripheral alkyl groups, we wondered what effect the introduction of fluorine substituents on the aromatic core would have. The least sterically disturbing position on the phenyl moieties is position 5, meta to both the central triazine and to the carboxylic substituent. We thus synthesized tris(fluorophenyl)triazine-trialkylesters $\mathbf{8}_{\mathrm{Me}}$, $\mathbf{8}_{\mathbf{E t}}, \mathbf{8}_{\mathrm{Pr}}, \quad \mathbf{8}_{\mathrm{Bu}}$ and $\mathbf{8}_{\text {pent. They all form }}$ an enantiotropic columnar mesophase with greatly extended temperature range (table 1 ) compared to their analogs with fluorinated chains instead of fluorinated core: Whilst their melting temperatures are lower than the fluorinated-chain analogs and are similar to those of the nonfluorinated analogs, their mesophases are stable up to considerably higher clearing temperatures, with $\mathbf{8}_{\mathbf{E t}}$ exhibiting an enantiotropic range of $97.2^{\circ} \mathrm{C}$ between the melting point at $156.1^{\circ} \mathrm{C}$ and the clearing point at $253.4{ }^{\circ} \mathrm{C}$. We were intrigued to find that even the methyl ester $\mathbf{8}_{\mathrm{Me}}$ exhibited an enantiotropic columnar mesophase over a few degrees, which contrasts with other columnar ester series such as triphenylene tricarboxylates $\mathbf{2}$ or perylene tetracarboxylates $\mathbf{9}$ (methyl ester not mesogenic in either family) or pyrene tetracarboxylates 10 (methyl ester monotropic). [5] The columnar mesophases of all homologs clearly exhibit homeotropic textures that testify of a hexagonal column lattice (Figure 1).

Whereas the mesophase ranges of the corefluorinated series $\mathbf{8}_{\mathbf{M e}}$ to $\mathbf{8}_{\text {pent }}$ are larger than those of the four analogous chain-fluorinated homologs $\mathbf{7}_{\mathbf{F} 2 \mathrm{Et}}$ to $\mathbf{7}_{\mathrm{F7Bu}}$, all members of the corefluorinated series crystallize during the DSC cooling runs at $-10{ }^{\circ} \mathrm{C} / \mathrm{min}$ to room temperature. $7_{\text {F2Et }}$ and $7_{\text {F3Et }}$ thus stand out amongst the fluorinated homologs by resisting crystallization under these conditions.

Having observed that the introduction of fluorine atoms in the alkyl chains of $\mathbf{7}$ induces an enantiotropic columnar mesophase (in contrast to the monotropic nematic mesophase of the nonfluorinated homologs), and that introduction of fluorine atoms in the aromatic core instead of in the chains further stabilizes the columnar mesophase leading to broad enantiotropic temperature ranges, we wondered what would happen if we would combine these two mesophase stabilizing modifications by introducing fluorine atoms both in the chains and in the core. We found that the two fluorine introductions largely cancel each other: All four doubly fluorinated derivatives that we subsequently made, $\mathbf{8}_{\text {F2Et }}, \mathbf{8}_{\text {F3Et, }}, \mathbf{8}_{\text {F5Pr }}$ and $\mathbf{8}_{\text {F7Bu, }}$ show dramatically increased melting temperatures and only monotropic mesophases, with a strong tendency to rapid crystallization on cooling, such that the mesophases could only be observed for short moments by POM upon fast cooling. Even more surprising, the tendency to mesomorphic ordering in the most fluorinated homolog $\mathbf{8}_{\mathrm{F} 7 \mathrm{Bu}}$ is so much reduced that only a nematic mesophase is observed, in contrast to the columnar mesophase of the three shorter-chained homologs. A mesophasestabilizing feature in the only chain-fluorinated or only core-fluorinated homologs thus seems to be nanosegregation between fluorinated outer and nonfluorinated inner parts of the molecule, or vice versa, which favors columnar stacking: If both the inner and the outer parts of the molecule are fluorinated, this mesophase-favoring nanosegregation effect is reduced, whereas molecular rigidity and thus easier crystalline packing is favored, leading to much higher melting points than of the nonfluorinated homologs. It is surprising though that only one fluorine atom per phenyl has such a significant effect on mesophase behavior, and other factors besides nanosegregation therefore have to play an important part as well. Dipolar and steric effects of the core fluorine atoms in 8 may be responsible for better columnar stacking, that in conjunction with flexible alkyl chains enhances mesophase stability, but in conjunction with rigid fluoroalkyl chains favors crystallinity whilst hindering fluidlike space filling. Symmetry-related steric mesophase stabilization may also in part explain the larger temperature range of the mesophase of $\mathbf{7}_{\mathbf{F} 2 \mathbf{E t}}$ compared to $7_{\text {F3Et }}$ : Whilst the latter, with more fluorines, stabilizes its mesophase up to a slightly higher clearing temperature, the former's less symmetric (more entropic) chains destabilize the crystalline state more efficiently and thus enable a larger enantiotropic mesophase range by lowering the melting temperature.
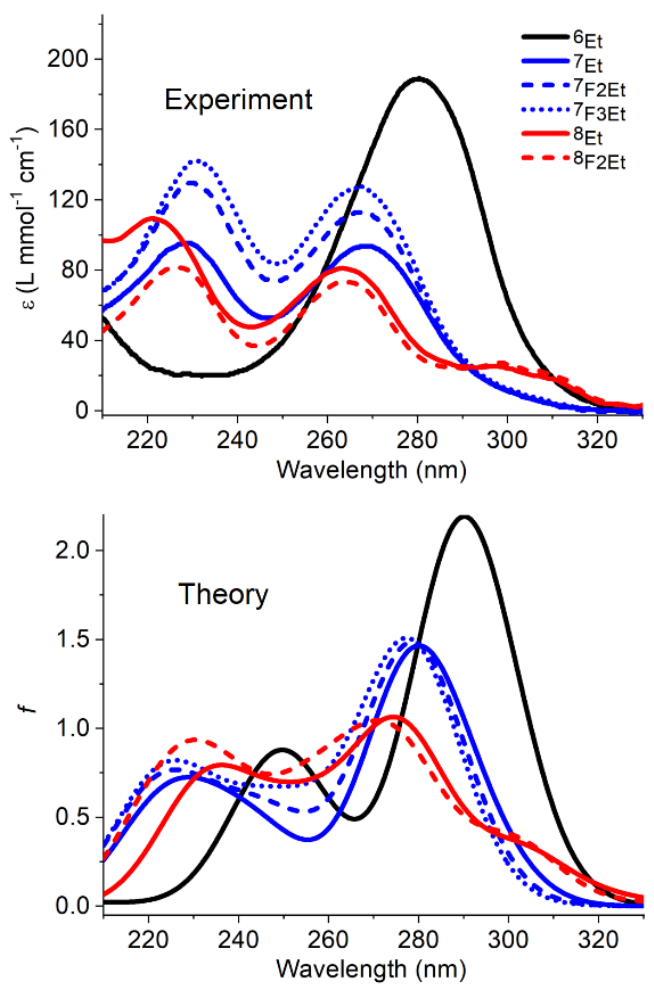

Figure 6. Top: Absorption spectra of compounds $\mathbf{6}_{\mathrm{Et}}, \mathbf{7}_{\mathrm{Et}}, \mathbf{7}_{\mathrm{F} 2 \mathrm{Et}}$, $\mathbf{7}_{\mathrm{FBEt}}, \quad \mathbf{8}_{\mathbf{E t}}$ and $\mathbf{8}_{\mathrm{F} 2 \mathrm{Et}}$ in acetonitrile solution. Bottom: Theoretical absorption spectra in vacuum obtained within B3LYP/def2-TZVP (-F) level of theory. The theoretical spectra are convoluted with Gaussians of $25 \mathrm{~nm}$ width.

The absorption spectra for the compounds $\boldsymbol{6}_{\mathbf{E t}}, \mathbf{7}_{\mathbf{E t}}$, $\mathbf{7}_{\text {F2Et }}, \mathbf{7}_{\text {F3Et }}, \mathbf{8}_{\mathbf{E t}}$ and $\mathbf{8}_{\mathbf{F 2 E t}}$ were recorded in acetonitrile solution, (Figure 6). These compounds were selected to evaluate the absorption properties of the meta/para substitution and the introduction of fluorine into in the aromatic core and in the alkyl chains. For $\boldsymbol{6}_{\mathbf{E t}}$ only one intense absorption band is observed at $280 \mathrm{~nm}$. On the other hand, the meta substituted compound $\mathbf{7}_{\mathbf{E t}}$ showed two intense 
absorption bands centered at 269 and $228 \mathrm{~nm}$. The introduction of fluorine into the alkyl chains for $\mathbf{7}_{\text {F2Et }}$ and $\mathbf{7}_{\text {F3Et }}$ resulted in a slight blue-shift of the absorption and an increase of the molar absorptivity. $\mathbf{8}_{\mathbf{E t}}$ and $\mathbf{8}_{\mathbf{F} \mathbf{E t}}$ showed an additional less intense band at lower energy with maxima around $298 \mathrm{~nm}$. For all compounds these transitions are assigned as $\Pi-\Pi^{*}-l i k e$. Furthermore, for all compounds no photoluminescence was observed in diluted solution when excited at the maximum of the lower energy absorption band.

To infer the energy level transitions of these molecules, we obtained the optimized geometry using DFT within B3LYP/def2-TZVP $(-F)$ level of theory. With the so-obtained geometry the timedependent DFT (TD-DFT) calculations were performed on ground and multiple excited states (see detailed TD-DFT analysis with difference densities of all molecules in supporting Information). The predicted absorption spectra (Figure 6) follow the same trends as observed experimentally. The TD-DFT analysis suggests that the lower energy band for $\mathbf{6}_{\mathrm{Et}}, \mathbf{7}_{\mathrm{Et}}, \mathbf{7}_{\mathrm{F} 2 \mathrm{Et}}$ and $\mathbf{7}_{\mathrm{F} 3 \mathrm{Et}}$ arises from many $\Pi-\Pi^{*}-l i k e$ transitions from benzene rings to the triazine moieties. Parahomolog $\mathbf{6}_{\mathbf{E t}}$ distinguishes itself from the metahomologs in that its higher symmetry leads to transitions with closer energy and thus to a more intense band. The introduction of fluorine into the alkyl chains increases the contribution of benzene rings to the transition, resulting in a higher oscillator strength and a rather small contribution of the carbonyl moiety, causing the band to blue-shift. For these compounds the high energy band is also a $\Pi-\Pi^{*}-l i k e$ transition, but in this case, it mainly involves the benzene rings and the acceptor orbitals have a contribution of the carbonyl moieties. The major difference for $\mathbf{8}_{\mathbf{E t}}$ and $\mathbf{8}_{\mathbf{F 2} \mathbf{E t}}$ is the low energy band that in this case is also resultant from $\Pi_{-\pi^{*}}$ like transitions, but the fluorine in the core results in a charge transfer characteristic from a benzene-fluorine to a triazine-benzene moiety. Considering that in the solid state the molecular packing should hinder the relaxation of the excited state we used the SOC approach for TDDFT to predict the $\mathrm{S}_{1}$ and $\mathrm{T}_{1}$ energy states (table 2). [42] The $S_{1}$ energy is in the range of 3.889 to $4.056 \mathrm{eV}$, while the $\mathrm{T}_{1}$ energy is the range of 3.120 to $3.300 \mathrm{eV}$. Such high energies of the lowlying excited singlet and triplet states above $3.0 \mathrm{eV}$, together with absence of fluorescence, support the suitability of these molecules as hosts for deep blue TADF emitters, whose triplet energies have to be close to $3 \mathrm{eV}$ and which necessitate a host matrix that has a slightly higher triplet energy to avoid unwanted energy transfers from guest to host.

Table 2. $\mathrm{S}_{1}$ and $\mathrm{T}_{1}$ vertical energies from SOC-TD-DFT for $\mathbf{6}_{\mathrm{Et}}, \mathbf{7}_{\mathrm{Et}}, \mathbf{7}_{\mathrm{F} 2 \mathrm{Et}}, \mathbf{7}_{\mathrm{F} 3 \mathrm{Et}}, \mathbf{8}_{\mathrm{Et}}$ and $\mathbf{8}_{\mathrm{F} 2 \mathrm{Et}}$ within B3LYP/def2-TZVP $(-\mathrm{F})$ level of theory.

\begin{tabular}{lllllll}
\hline & $\boldsymbol{6}_{\mathrm{Et}}$ & $\mathbf{7}_{\mathrm{Et}}$ & $\mathbf{7}_{\mathrm{F} 2 \mathrm{Et}}$ & $\mathbf{7}_{\mathrm{F} 3 \mathrm{Et}}$ & $\mathbf{8}_{\mathrm{Et}}$ & $\mathbf{8}_{\mathrm{F} 2 \mathrm{Et}}$ \\
\hline $\begin{array}{l}\mathrm{S}_{1} \\
(\mathrm{eV})\end{array}$ & 3.889 & 4.056 & 4.054 & 4.054 & 4.016 & 4.028 \\
$\mathrm{~T}_{1}$ & 3.120 & 3.293 & 3.300 & 3.300 & 3.259 & 3.267 \\
$(\mathrm{eV})$ & & & & & & \\
\hline
\end{tabular}

Combining such suitably high triplet energies with alignment of the liquid crystalline matrix molecules parallel to the substrate surface on the one hand, and with persistence of a highviscosity liquid crystalline state at room temperature (as observed with $\mathbf{7}_{\mathbf{F} 2 \mathbf{E t}}$ and its 1:1 mixture with $\mathbf{7}_{\mathbf{E t}}$ ) on the other hand would enable improved light outcoupling and thus external quantum efficiencies of deep blue TADF devices as compared with devices based on conventional isotropic emitter layers. ${ }^{[1]}$ The development of device-compatible alignment procedures as well as detailed studies of the glassy state of the aligned materials depending on thermal history and confinement conditions are perspectives for the future opened by this work.

\section{Conclusion}

In summary, conformationally flexible triphenyls-triazines with alkyl ester substitutents in symmetry-reducing meta-positions form nematic mesophases, rare in disk-shaped systems. Albeit monotropic, the nematic state persists at room temperature for many hours in the ethyl homolog after fast cooling from the isotropic liquid.

The introduction of fluorine atoms in the alkyl chains dramatically enhances the degree of order in the mesophase, leading to the appearance of an enantiotropic columnar mesophase. If a fluorine atom is introduced in each of the three phenyl moieties instead, the stability of the columnar mesophase is further enhanced, leading to large enantiotropic temperature ranges. If both the alkyl chains and the aromatic core are fluorinated, the mesophase is destabilized to monotropic columnar in the short chain homologs, and to monotropic nematic with longer fluorinated chains. Thus fluorination of only chains or only core enhances periodic mesogenic self-assembly, whereas fluorination of both cancels out this effect.

In the columnar materials, the quality of longrange intercolumnar periodicity is dependent on thermal history (as testified by the appearance of secondary lattice peaks in the powder X-ray diffractogram), illustrating the sensitivity of mesogenic order to minor perturbations. The columnar mesophase can even be perturbed further to induce a change of mesophase: By mixing a columnar homolog with a nonmesogenic homolog, a nematic mesophase is induced that is observed with neither of the pure materials. This underscores that both the columnar and the nematic mesophases are of similar structure based on columnar short range stacking.

From UV-visible absorption spectra combined with SOC-TD-DFT calculations, energies of the $\mathrm{S}_{1}$ and $\mathrm{T}_{1}$ excited states in excess of $3 \mathrm{eV}$ are obtained, qualifying this synthetically very accessible and non-emissive family of mesogens as potential anisotropic hosts for deep blue TADF emitters in luminescent devices for alignment-induced enhancement of light outcoupling. 


\section{Acknowledgements}

We are grateful to INCT/INEO, CNPq, FAPESC, H2020-MSCA-RISE-2017 (OCTA, \#778158), CAPES

(Coordenação de aperfeiçoamento de pessoal de nível superior, Brazil, \#937-20) and COFECUB (Comité français d'évaluation de la coopération universitaire et scientifique avec le Brésil) (joint project Ph-C 962/20) for support. The XRD experiments were carried out in the Laboratório de Difração de Raios X (LDRX/UFSC).

Keywords: Cyclotrimerization • Mesophases • Fluorine - Substituent effects - Triplet energy

[1] C. Destrade, M. C. Mondon, J. Malthête, J. Physique 1979, C3, 17-21.

[2] S. Chandrasekhar, B. K. Sadashiva, K. A. Suresh, Pramana 1977, 9, 471-480.

[3] T. Wöhrle, I. Wurzbach, J. Kirres, A. Kostidou, N. Kapernaum, J.Litterscheidt, J. C. Haenle, P. Staffeld, A. Baro, F. Giesselmann, S. Laschat, Chem. Rev. 2016, $116,1139-1241$.

[4] S. Laschat, A. Baro, N. Steinke, F. Giesselmann, C. Hägele, G. Scalia, R. Judele, E. Kapatsina, S. Sauer, A. Schreivogel, M. Tosoni, Angew. Chem. Int. Ed. 2007, 46, 4832-4887; Angew. Chem. 2007, 119, 4916-4973.

[5] T. Hassheider, S. A. Benning, H.-S. Kitzerow, M.F. Achard, H. Bock, Angew. Chem. Int. Ed. 2001, 40, 2060-2063; Angew. Chem. 2001, 113, 2119-2122.

[6] H. Bock, M. Rajaoarivelo, S. Clavaguera, É. Grelet, Eur. J. Org. Chem. 2006, 2889-2893.

[7] J. Kelber, M.-F. Achard, B. Garreau-de Bonneval, H. Bock, Chem. Eur. J. 2011, 17, 8145-8155.

[8] H. Bock, A. Babeau, I. Seguy, P. Jolinat, P. Destruel, ChemphysChem 2002, 6, 532-535.

[9] F. B. Dias, T. J. Penfold, A. P. Monkman, Methods Appl. Fluoresc. 2017, 5, 012001.

[10] Y. Tao, K. Yuan, T. Chen, P. Xu, H. Li, R. Chen, C. Zheng, L. Zhang, W. Huang, Adv. Mater. 2014, 26, 79317958 .

[11] Z. Yang, Z. Mao, Z. Xie, Y. Zhang, S. Liu, J. Zhao, J. Xu, Z. Chi, M. P. Aldred, Chem. Soc. Rev. 2017, 46, $915-$ 1016.

[12] Y. Wada, K. Shizu, S. Kubo, K. Suzuki, H. Tanaka, C. Adachi, H. Kaji, Appl. Phys. Lett. 2015, 107, 183303.

[13] X. Cai, S.-J. Su, Adv. Funct. Mater. 2018, 28, 1802558.

[14] T.-T. Bui, F. Goubard, M. Ibrahim-Ouali, D. Gigmes, F. Dumur, Beilstein J. Org. Chem. 2018, 14, 282-308.

[15] X.-K. Chen, Y. Tsuchiya, Y. Ishikawa, C. Zhong, C. Adachi, J.-L. Bredas, Adv. Mater. 2017, 29, 1702767.

[16] X. Ban, W. Jiang, T. Lu, X. Jing, Q. Tang, S. Huang, K. Sun, B. Huang, B. Lin, Y. Sun, J. Mater. Chem C 2016, 4, $8810-8816$

[17] L.-S. Cui, H. Nomura, Y. Geng, J. U. Kim, H. Nakanotani, C. Adachi, Angew. Chem. Int. Ed. 2017, 56, 1571-1575; Angew. Chem. 2017, 129, 1593-1597.

[18] M. Kim, S. K. Jeon, S.-H. Hwang, J. Y. Lee, Adv. Mater. $2015,27,2515-2520$.

[19] W. Huang, M. Einzinger, A. Maurano, T. Zhu, J. Tiepelt, C. Yu, H. S. Chae, T. Van Voorhis, M. A. Baldo, S. L. Buchwald, Adv. Optical Mater. 2019, 7, 1900476.

[20] C. S. Oh, D. de Sa Pereira, S. H. Han, H.-J. Park, H. F. Higginbotham, A. P. Monkman, J. Y. Lee, ACS Appl. Mater. Interfaces 2018, 10, 35420-35429.

[21] S. Brinen, J. G. Koren, W. G. Hodgson, J. Chem. Phys. 1966, 44, 3095-3099.

[22] T. Marcato, C.-J. Shih, Helv. Chim. Acta 2019, 102, e1900048.

[23] C. Bishop, J. L. Thelen, E. Gann, M. F. Toney, L. Yu, D. M. DeLongchamp, M. D. Ediger, Proc. Natl. Acad. Sci. USA 2019, 116, 21421-21426.

[24] M. D. Ediger, J. de Pablo, L. Yu, ACC. Chem. Res. 2019, 52, 407-414.

[25] T. Komino, Y. Sagara, H. Tanaka, Y. Oki, N. Nakamura, H. Fujimoto, C. Adachi, Appl. Phys. Lett. 2016, 108, 241106.
26] H. Tanaka, H. Noda, H. Nakanotani, C. Adachi, Appl. Phys. Lett. 2020, 116, 023302.

[27] A. Gujral, J. Gómez, S. Ruan, M. F. Toney, H. Bock, L. Yu, M. D. Ediger, Chem. Mater. 2017, 29, 9110-9119.

[28] J. Eccher, G. C. Faria, H. Bock, H. von Seggern, I. H. Bechtold, ACS Appl. Mater. Interfaces 2013, 5, 1193511943.

[29] L.-S. Cui, S.-B. Ruan, F. Bencheikh, R. Nagata, L. Zhang, K. Inada, H. Nakanotani, L.-S. Liao, C. Adachi, Nat. Commun. 2017, 8, 2250

[30] E. W. Crandall, L. Harris, Org. Prep. Proced. 1969, 1, $147-156$.

[31] H. Taing, J. G. Rothera, J. F. Binder, C. L. B. Macdonald, S. H. Eichhorn, Liq. Cryst. 2018, 45, 1147-1154.

[32] G. Martins Filho, J. Goncalves da Costa, F. Soares de Azevedo, J. O. Falcão de Morais, Anais Acad. Bras. Ciencias 1963, 35, 185-195.

[33] W. Zhang, C. Zhu, Z. Huang, C. Gong, Q. Tang, X. Fu, Org. Electronics 2019, 67, 302-310.

[34] H. Bengs, O. Karthaus, H. Ringsdorf, C. Baehr, M. Ebert, J. H. Wendorff, Liq. Cryst. 1991, 10, 161-168.

[35] S. Hayami, K. Inoue, Chem. Lett. 1999, 28, 545-546.

[36] M. G. Freire, A. G. M. Ferreira, I. M. A. Fonseca, I. M. Marrucho, J. A. P. Coutinho, J. Chem. Eng. Data 2008, 53, 538-542.

[37] R. Pollice, P. Chen, J. Am. Chem. Soc. 2019, 141, 34893506 .

[38] N. Terasawa, H. Monobe, K. Kiyohara, Y. Shimizu, Chem. Commun. 2003, 1678-1679.

[39] N. Terasawa, H. Monobe, K. Kiyohara, Liq. Cryst. 2007 $34,311-324$

[40] A. T. Proudfoot, S. M. Bradberry, J. A. Vale, Toxicol. Rev. 2006, 25, 213-219.

[41] Nguyen H. T., J. Malthête, C. Destrade, J. Physique Lett. $1981,42,417-419$.

[42] B. Souza, G. Farias, F. Neese, R. Izsák, J. Chem. Theory Comp. 2019, 15, 1896-1904. 
